Review

\title{
Development and Applications of Ruggedized VIS/NIR Spectrometer System for Oilfield Wellbores
}

\author{
Go FUJISAWA $^{1^{*}}$ and Tsutomu YAMATE ${ }^{2}$ \\ ${ }^{1}$ Schlumberger Gould Research, Cambridge, UK \\ ${ }^{2}$ Schlumberger K.K., Sagamihara, Japan \\ *Corresponding author: Go FUJISAWA_ E-mail: gfujisawa@slb.com
}

\begin{abstract}
The development and applications of a ruggedized visible to near-infrared (VIS/NIR) spectrometer system capable of measuring fluid spectra in oilfield wellbores are presented. Real-time assessment of formation fluid properties penetrated by an oilfield wellbore is critically important for oilfield operating companies to make informed decisions to optimize the development plan of the well and hydrocarbon reservoir. A ruggedized VIS/NIR spectrometer was designed and built to measure and analyze hydrocarbon spectra reliably under the harsh conditions of the oilfield wellbore environment, including temperature up to $175^{\circ} \mathrm{C}$, pressure up to $170 \mathrm{MPa}$, and severe mechanical shocks and vibrations. The accuracy of hydrocarbon group composition analysis was compared well with gas chromatography results in the laboratory.
\end{abstract}

Keywords: VIS/NIR spectroscopy, hydrocarbon compositions, oilfield wellbore, in situ measurement, real time

Citation: Go FUJISAWA and Tsutomu YAMATE, "Development and Applications of Ruggedized VIS/NIR Spectrometer System for Oilfield Wellbores," Photonic Sensors, DOI: 10.1007/s13320-013-0126-3.

\section{Introduction}

Timely in-situ assessment of formation fluid penetrated by an oilfield wellbore is critically important to enable informed decisions to optimize the development plan of the well and hydrocarbon reservoir. A visible to near-infrared (VIS/NIR) spectrometer is the ideal instrument to identify and analyze hydrocarbon found in oil and gas fields; however, the harsh environments prohibit the deployment of conventional commercial spectrometers that will not survive at the high temperature, high pressure, and mechanical shock and vibration conditions of a typical oil and gas well.

We designed and built a ruggedized VIS/NIR spectrometer system that could measure hydrocarbon spectra at the environmental temperature up to $175{ }^{\circ} \mathrm{C}$ and pressure up to $170 \mathrm{MPa}$. The spectrometer optical alignment was designed to withstand the severe mechanical shocks and vibrations expected for oilfield uses.

The majority of molecules found in the formation fluid of oilfields are hydrocarbon and water. Small concentrations of carbon dioxide, hydrogen sulfide, and nitrogen are also detected in some oil and gas wells. As is clear from Fig. 1, the VIS/NIR spectroscopy can identify water and hydrocarbon by their respective vibration peaks, characterize hydrocarbon types (i.e., heavy oil, black oil, volatile oil, and condensate) by their continuous absorption tail, and determine the grouped

Received: 16 July 2013 / Revised version: 26 August 2013

(C) The Author(s) 2013. This article is published with open access at Springerlink.com 
hydrocarbon composition by the detailed analysis of the carbon-hydrogen vibrational overtone band in the 1700-nm region. In addition, carbon dioxide can be detected by measuring its absorption bands at approximately $2000 \mathrm{~nm}$, as long as no appreciable water is present.

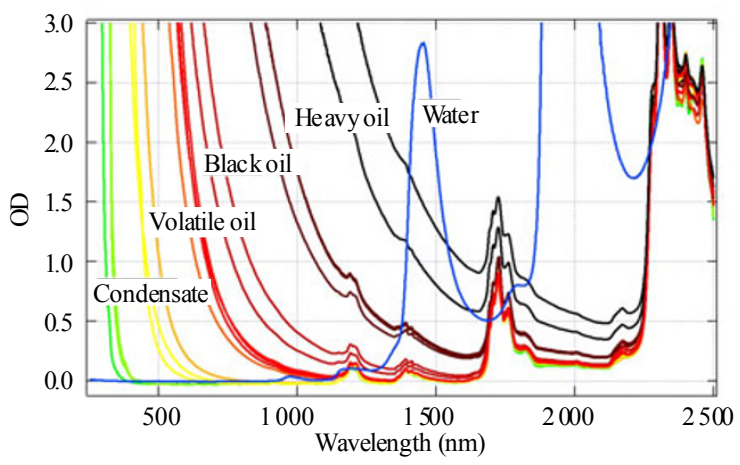

Fig. 1 VIS/NIR absorption spectra of typical fluids in oilfield formations and wellbores, which were measured at the 2-mm optical path length.

Several studies have shown that the hydrocarbon composition can be determined with a spectrometer with limited channels and resolutions at high pressure and temperature [1-4]. Thus, ruggedized VIS/NIR spectrometer designs with limited channels and resolutions are often sufficient for oilfield wellbore applications.

Engineering factors also favor the VIS/NIR spectroscopy over other measurement technologies, such as gas chromatography, NMR measurement, and mass spectroscopy. A ruggedized VIS/NIR spectrometer system can be built by coupling an optical bandpass filter and detector for each wavelength of interest. The required technologies to build such a spectrometer already exist. Tungsten halogen lamps, optical fibers, optical filters, and silicon- or InGaAs-based semiconductor photodetectors are relatively robust technologies even at oilfield temperatures. Sapphire is the perfect material for the optical window because it is transparent in the entire VIS/NIR range, and it is also hard enough to seal and protect the rest of the sensitive spectrometer system from the high pressure of the oil wellbore. Unlike a conventional grating spectrometer or a Fourier transform infrared (FTIR) spectrometer, this design does not have any moving mechanical parts in the optics, thus the system and its optical alignment can survive the severe shocks and vibrations experienced in oilfield uses. For these reasons, the VIS/NIR spectroscopy has been widely used as the most accepted technology to investigate the formation fluid in-situ since its introduction almost 20 years ago [5].

In this review, we report the development and applications of a latest generation VIS/NIR spectrometer that can measure the hydrocarbon spectrum more accurately and in greater detail than previous VIS/NIR spectrometers.

\section{Key design considerations}

There are several factors that determine the accuracy of spectroscopic measurement, signal baseline stability, signal resolution, signal dynamic range, wavelength stability, wavelength resolution, and wavelength coverage. For oil wellbore applications, the most critical factors are signal baseline stability and wavelength stability.

Spectrometers for the oil wellbores have a very unique and demanding requirement for signal baseline stability. For laboratory spectroscopic measurement, a signal baseline is typically measured before sample spectra are measured under the same laboratory environment. However, this practice is not possible for oilfield wellbore applications. A spectrometer signal baseline is typically measured on the surface (at a base or wellsite), but actual sample spectra measurements take place several thousand meters beneath the surface at different temperatures and pressures. The spectrometer may also experience severe mechanical shocks and vibrations during conveyance, i.e., between the signal baseline measurement on the surface and actual sample measurement in the wellbore. Thus, the signal baseline needs to remain unchanged against these outside events. 
The requirement for wavelength stability comes from the same reason as that for the signal baseline stability. Since the wavelength calibration inside a wellbore is not very practical, the central wavelength and transfer function for each wavelength channel need to remain the same under conditions of different temperatures and mechanical shocks and vibrations.

Other requirements include the high pressure (up to $170 \mathrm{MPa})$ and high temperature $\left(175^{\circ} \mathrm{C}\right)$ expected in some wellbores. Small space is another design constraint as the spectrometer system needs to be installed inside a cylindrical oilfield tool about $10 \mathrm{~cm}$ in diameter.

To satisfy these unique sets of environmental requirements while maximizing the wavelength coverage, we designed our spectrometer system to include a 20-channel filter array spectrometer and a 16-channel grating spectrometer. The 20-channel filter array spectrometer used 20 sets of detectors coupled with an optical bandpass filter for each wavelength. It measured 20 discrete wavelength channels from $450 \mathrm{~nm}$ to $2000 \mathrm{~nm}$, covering hydrocarbon fluid color absorption, water peaks, hydrocarbon peaks, and $\mathrm{CO}_{2}$ peaks (Fig. 1). The 16-channel grating spectrometer used a fixed grating and a 16-channel InGaAs detector array. It measured 16 evenly spaced wavelengths between $1600 \mathrm{~nm}$ and $1800 \mathrm{~nm}$, giving the details of hydrocarbon peaks. All components that could influence the optical path were firmly fixed to minimize misalignment risks under mechanical shocks, vibrations, and temperature changes.

Figure 2 shows the schematic drawing of the developed system. A halogen tungsten light illuminates the fluid inside the high-pressure flowline coupled by a pair of the sapphire optical windows. Transmitted light is collected by optical fiber bundles and guided into the 20-channel filter array spectrometer and 16-channel grating spectrometer. In addition to the spectrometer system, we developed a ruggedized fluorescence detection unit. It used a blue light-emitting diode (LED) as the excitation light source and detected fluorescence signals at two different wavelengths. A reflection signal was also measured. The fluorescence and reflection measurements are useful particularly when multiphase fluid is present in the flowline.

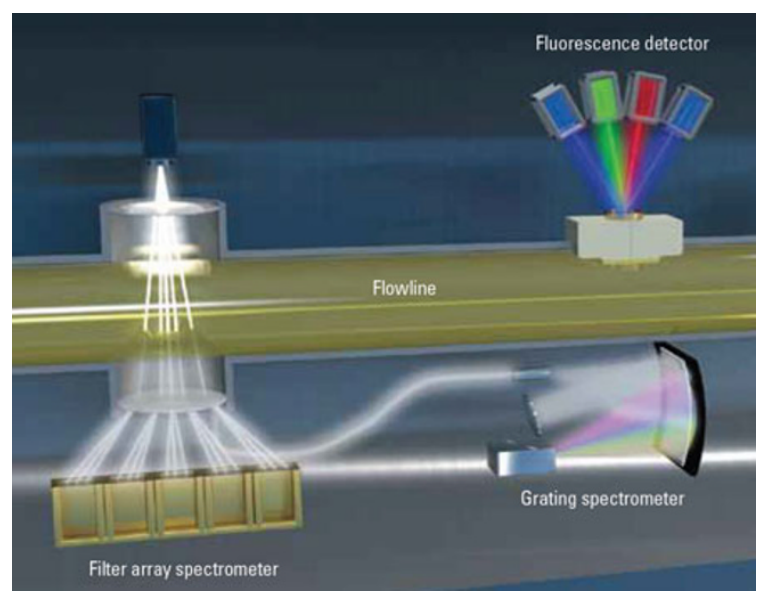

Fig. 2 Schematic drawing of the developed system that consisted of a 20-channel filter array spectrometer, a 16-channel grating spectrometer, and a fluorescence detector unit.

\section{Spectrometer performance}

The stability of the signal baseline and wavelength were extensively tested for mechanical shocks, vibrations, and temperature variations for both the filter-array spectrometer and grating spectrometer at the components level, unit level, and system level. For the temperature variation test, an automated calibration was allowed to mitigate the impact of the thermal expansion. In spite of these severe environmental conditions, the spectrometer system demonstrated the required stability to perform accurate spectroscopic measurement.

As a final confirmation of this spectrometer performance, we developed a unique interpretation algorithm for this spectrometer system to determine the hydrocarbon group compositions $\left(\mathrm{C}_{1}, \mathrm{C}_{2}, \mathrm{C}_{3}-\mathrm{C}_{5}\right.$, $\mathrm{C}_{6+}$, and $\mathrm{CO}_{2}$ ). Many comparison tests were performed for various single-phase hydrocarbon fluids under high pressure and high temperature. The hydrocarbon group compositions determined in real time by this spectrometer system compared very 
well with gas chromatography analysis performed later in the laboratory (Fig. 3).

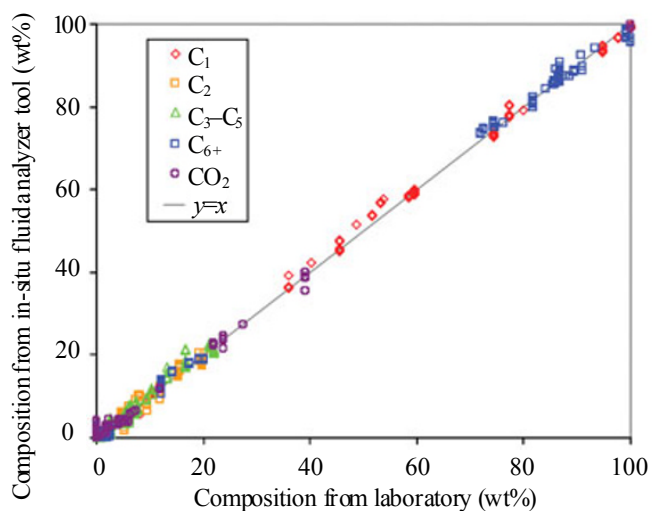

Fig. 3 Comparison of the measured fluid composition groups $\left(\mathrm{C}_{1}, \mathrm{C}_{2}, \mathrm{C}_{3}-\mathrm{C}_{5}, \mathrm{C}_{6+}\right.$, and $\left.\mathrm{CO}_{2}\right)$ between laboratory gas chromatography (horizontal axis) and this spectrometer system at high temperature and high pressure (vertical axis).

\section{Applications}

The developed spectrometer system is brought into a wellbore as a part of the formation testing toolstring (Fig. 4).

The typical formation testing toolstring consists of several functional modules. When the toolstring descends to the depth of interest in a wellbore, a probe module is activated, and a sealed fluid connection between the hydrocarbon-bearing formation and toolstring is created. Then, a pump module moves the formation fluid from the formation to inside the toolstring. The fluid initially flowing into the toolstring is typically heavily contaminated with drilling fluid and is of little use. As more time is spent for the pumping fluid, less-contaminated formation fluid is obtained. The spectrometer module monitors the flowing fluid inside the toolstring by measuring its fluid spectrum continuously. If the fluid inside the toolstring is sufficiently clean and worthy of further laboratory analysis, it is captured and stored inside the sample-bottle module.

The applications of the spectrometer system fall into three broad categories: sampling program optimization, sampling quality assurance, and measuring properties that are difficult to measure in the laboratory.

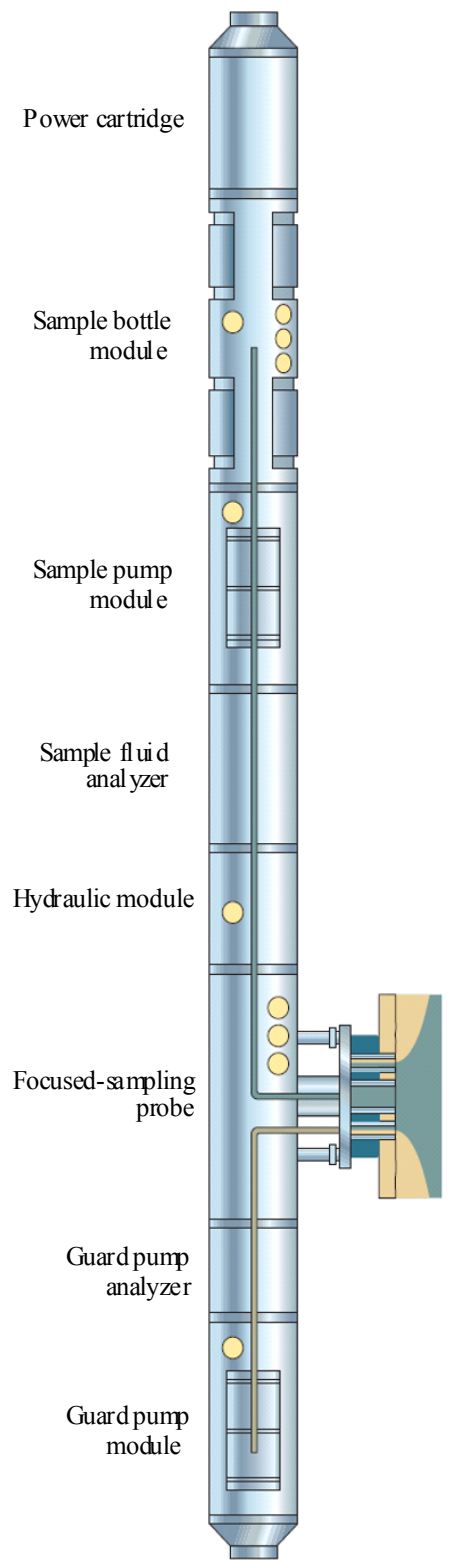

Fig. 4 Example of a formation testing toolstring containing a sample fluid analyzer including the spectrometer system.

The sampling program optimization is an iterative process of real-time fluid analysis and decision making. In the past, the fluid sampling program was mostly executed by following a predetermined program based on other formation property data but not fluid data. With real-time accurate spectroscopy data, it is now realized that 
fluids inside the formation are often more variable, and the proper assessment of their variations is the key for the future success of the hydrocarbon production. Currently, the fluid sampling program is flexible and is executed based on the real-time data available from spectroscopic measurement. There are many case studies for those interested to know the applications for the spectrometer in the oil field $[6,7]$.

The sampling quality assurance is the process used to capture representative formation fluid into a sample bottle for further analysis in the laboratory. For the formation fluid to be representative, it must be captured under a single phase and with sufficiently low contamination from the drilling fluid. Continuous spectroscopic measurement can provide vital information to satisfy both of these conditions in real time $[5,8,9]$.

Some fluid properties are known to be difficult to be analyzed in the laboratory. For example, in-situ $\mathrm{pH}$ measurement of water at reservoir pressure and temperature can be carried out by mixing formation water and $\mathrm{pH}$-sensitive color dye, then the measurement of the water color can be done by the spectrometer [10]. In contrast, the laboratory $\mathrm{pH}$ measurement is typically conducted at surface pressure and temperature, and the dissolved gas and minerals may come out of the original solution. This naturally results in a different $\mathrm{pH}$ value, and it requires correction.

\section{Conclusions}

We developed a ruggedized VIS/NIR spectrometer system that consisted of a 20-channel filter array spectrometer and a 16-channel grating spectrometer. The spectrometer system is able to measure hydrocarbon group compositions $\left(\mathrm{C}_{1}, \mathrm{C}_{2}\right.$, $\mathrm{C}_{3}-\mathrm{C}_{5}, \mathrm{C}_{6+}$, and $\mathrm{CO}_{2}$ ) at high pressure and high temperature typical of oilfield formations and wellbores, and its results compared well with gas chromatography measurements performed in the laboratory. Several references are included for those interested in knowing about applications for the spectrometer in the oilfield [5-10]. More than 100 of the spectrometer systems were manufactured and deployed to perform invaluable real-time spectroscopic measurement in oilfield wellbores worldwide.

\section{Acknowledgment}

These activities were done for the Schlumberger InSitu Fluid Analyzer* project.

Open Access This article is distributed under the terms of the Creative Commons Attribution License which permits any use, distribution, and reproduction in any medium, provided the original author(s) and source are credited.

\section{References}

[1] C. W. Brown, "Trading wavelength for absorbance resolution: predicting the performance of array detection systems," Applied Spectroscopy, vol. 47, no. 5, pp. 619-624, 1993.

[2] O. C. Mullins, T. Daigle, C. Crowell, H. Groenzin, and N. B. Joshi, "Gas-oil ratio of live crude oils determined by near-infrared spectroscopy," Applied Spectroscopy, vol. 55, no. 2, pp. 197-201, 2001.

[3] M. A. van Agthoven, G. Fujisawa, P. Rabbito, and O. C. Mullins, "Near-infrared spectral analysis of gas mixtures," Applied Spectroscopy, vol. 56, no. 5, pp. 593-598, 2002.

[4] G. Fujisawa, M. A. van Agthoven, F. Jenet, P. A. Rabbito, and O. C. Mullins, "Near-infrared compositional analysis of gas and condensate reservoir fluids at elevated pressures and temperatures," Applied Spectroscopy, vol. 56, no. 12, pp. 1615-1620, 2002.

[5] A. R. Smits, D. V. Fincher, K. Nishida, O. C. Mullins, R. J. Schroeder, and T. Yamate, "In-situ optical fluid analysis as an aid to wireline formation sampling," SPE Formation Evaluation, ,vol. 10, no. 2, pp. 91-98, 1995.

[6] J. Creek, M. Cribbs, C. Dong, O. C. Mullins, H. Elshahawi, P. Hegeman, et al., "Downhole fluids

\footnotetext{
${ }^{*}$ Mark of Schlumberger
} 
laboratory," Oilfield Review, vol. 21, no. 4, pp. 38-54, 2009/2010.

[7] O. C. Mullins, The Physics of reservoir fluids: discovery through downhole fluid analysis. Sugar Land, Texas, U.S.A.: Schlumberger, 2008.

[8] O. C. Mullins, J. Schroer, and G. F. Beck, "Real-time quantification of OBM filtrate contamination during openhole wireline sampling by optical spectroscopy," presented at SPWLA 41st Annual Logging Symposium, SS, Houston, Texas, USA, June 4-7,
2000.

[9] S. Betancourt, G. Fujisawa, O. C. Mullins, A. Carnegie, C. Dong, A. Kurkjian, et al., "Analyzing hydrocarbons in the borehole," Oilfield Review, vol. 15 , no. 3, pp. 54-61, 2003.

[10] B. Raghuraman, M. O'Keefe, K. O. Eriksen, L. A. Tau, O. Vikane, G. Gustavson, et al., "Real-time downhole $\mathrm{pH}$ measurement using optical spectroscopy," SPE Reservoir Evaluation \& Engineering, vol. 10, no. 7, pp. 302-311, 2007. 